\title{
Polymer-Assisted Hydrothermal Synthesis of Hierarchically Arranged Hydroxyapatite Nanoceramic
}

\author{
A. Joseph Nathanael, Sung Soo Han, and Tae Hwan Oh \\ Department of Nano, Medical and Polymer Materials, College of Engineering, Yeungnam University, \\ Gyeongsan 712749, Republic of Korea
}

Correspondence should be addressed to Tae Hwan Oh; taehwanoh@ynu.ac.kr

Received 3 May 2013; Accepted 18 June 2013

Academic Editor: Eng San Thian

Copyright (C) 2013 A. Joseph Nathanael et al. This is an open access article distributed under the Creative Commons Attribution License, which permits unrestricted use, distribution, and reproduction in any medium, provided the original work is properly cited.

\begin{abstract}
Flower-like hydroxyapatite (HA) nanostructures were synthesized by a polymer-assisted hydrothermal method. The thickness of the petals/plates decreased from $200 \mathrm{~nm}$ to $40 \mathrm{~nm}$ as the polymer concentration increased. The thickness also decreased as the hydrothermal treatment time increased from 6 to $12 \mathrm{hr}$. The HRTEM and SAED patterns suggest that the floral-like HA nanostructures are single crystalline in nature. Structural analysis based on XRD and Raman experiments implied that the produced nanostructure is a pure form of HA without any other impurities. The possible formation mechanism was discussed for the formation of flower-like HA nanostructures during polymer-assisted hydrothermal synthesis. Finally, in vitro cellular analysis revealed that the hierarchically arranged HA nanoceramic had improved cell viability relative to other structures. The cells were actively proliferated over these nanostructures due to lower cytotoxicity. Overall, the size and the crystallinity of the nanostructures played a role in improving the cell proliferation.
\end{abstract}

\section{Introduction}

The functional properties of inorganic compounds or inorganic/organic hybrids are related to their shape, size, and dimension [1-4]. Three-dimensional (3D) nano/microstructures have recently received a great deal of attention in material science research [5-8]. Substantial developments have been made in the fabrication of three-dimensional nanomaterials and they are now applied in optoelectronic devices [9], drug delivery systems [10], sensors [11], super capacitors $[12,13]$, and as catalysts [2]. Formations of uniform hierarchical superstructures using nanoparticles such as nanorods, nanoplates, and nanospheres with diameters ranging from nano- to microscale dimensions are especially desirable due to their interesting functional properties.

Tunable functional properties of inorganic materials have been achieved by the self-assembly of their nanoparticles into nanostructures [14]. These functional properties of the nanostructures are dependent on the design and control of the size, shape, and orientation of the building blocks. Investigations of the self-assembly of two-dimensional (2D) and three-dimensional (3D) nanoparticles have expanded rapidly $[15,16]$ because of their fascinating functional properties and potential applications in various fields [17].

In the human body, the structure of bone displays a hierarchical arrangement, but it differs significantly at different locations. Nevertheless, mineralized collagen consisting of the basic nanoscale structure of bone remains the same $[18,19]$. It has been reported that nanorods such as crystals of hydroxyapatite (HA) are deposited parallel with the $c$ axis aligned with the long axis in calcified tissues [20, 21]. Additionally, experiments have shown that the biocompatibility and bioactivity of bone cells on HA are enhanced by the oriented structure of HA [22]. Hence, this structure encourages the design and fabrication of biomaterials.

Hydroxyapatite ( $\mathrm{HA}, \mathrm{Ca}_{10}\left(\mathrm{PO}_{4}\right)_{6}(\mathrm{OH})_{2}$ ) has been widely used in biomedicine as filler [20], for bone repair and bone tissue regeneration [23], and as a drug delivery carrier owing to its good biocompatibility and bioactivity and its high osteoconductive and/or osteoinductive properties [20,22]. HA is the most stable calcium phosphate phase under physiological conditions and exists all over the human body as 


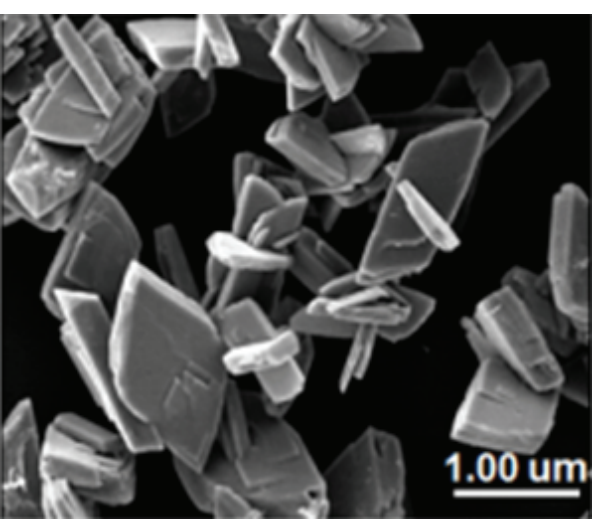

(a)

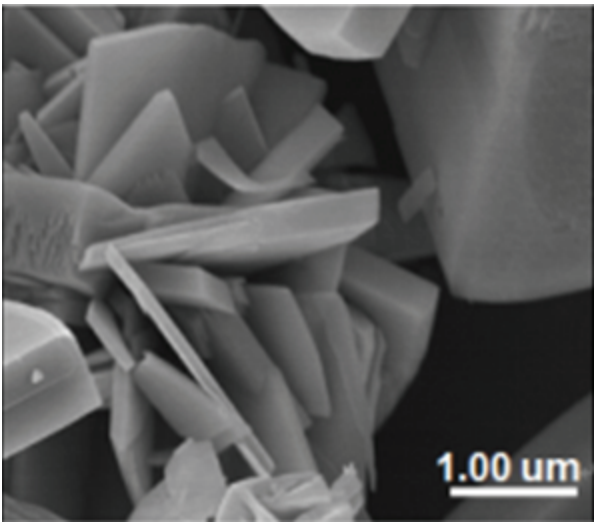

(c)

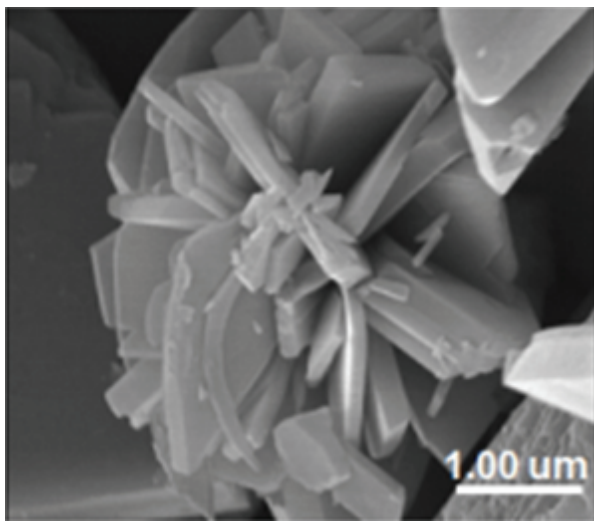

(e)

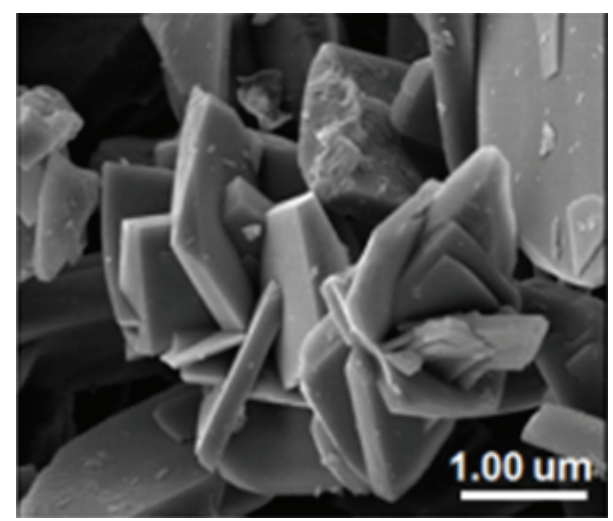

(b)

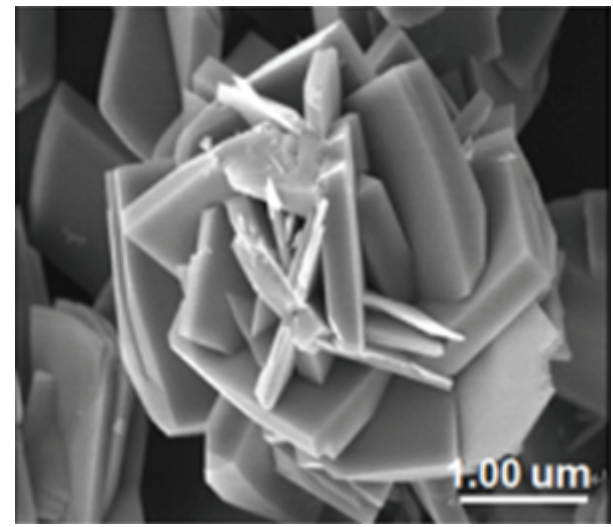

(d)

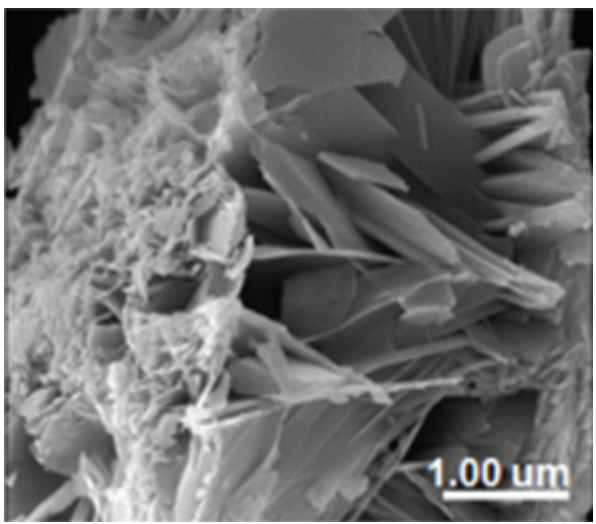

(f)

FIGURE 1: FESEM images of polymer-assisted HA nanostructures with PAM concentrations of 2, 3, and $4 \mathrm{~g} / \mathrm{L}$ (a, c, and e) and hydrothermal reaction times of $6 \mathrm{hr}$ and (b, d, and f) $12 \mathrm{hr}$.

the main inorganic constituent of bone and teeth [24]. HA also has many important industrial and biomedical applications in catalysis, ion exchange, sensors, and bioceramics [2, $10,11]$. HA is a polar hexagonal and highly anisotropic crystal that naturally grows into a $1 \mathrm{D}$ nanostructure [17]. Nanostructured HA possesses higher specific surface areas that enhance the adhesion of cells, proteins, and drugs. Hence, the miniaturization of size and tuning of the morphology are an important factor for current biomedical research [23].
Many previous reports have shown that polymers such as PEG (poly(ethylene glycol)) [25-28], PVP (polyvinyl pyrrolidone) [29, 30], and PAM (polyacrylamide) [31] are useful components in the formation of one- and zero-dimension nanosized materials. Some studies have investigated the preparation of nanomaterials such as $\mathrm{ZnO}[25,29,31], \mathrm{MoO}_{2}$ whiskers [26], and $\mathrm{Al}_{2} \mathrm{O}_{3}-\mathrm{TiO}_{2}$ composite nanoparticles [27] using polymer-assisted synthesis. PEG-assisted HA nanoparticle synthesis was reported by Tseng et al. [28], while metal 


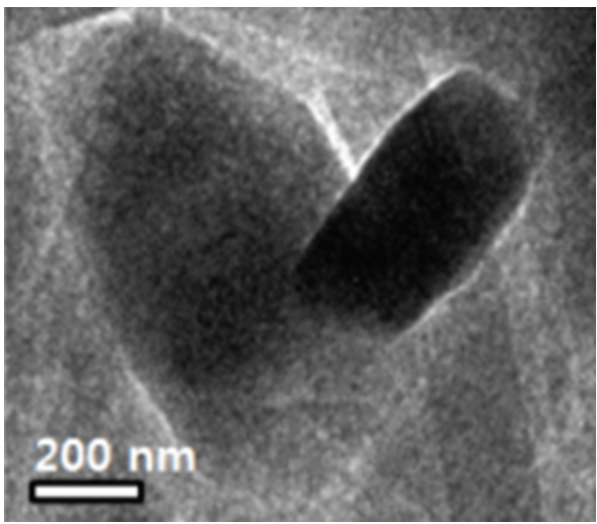

(a)

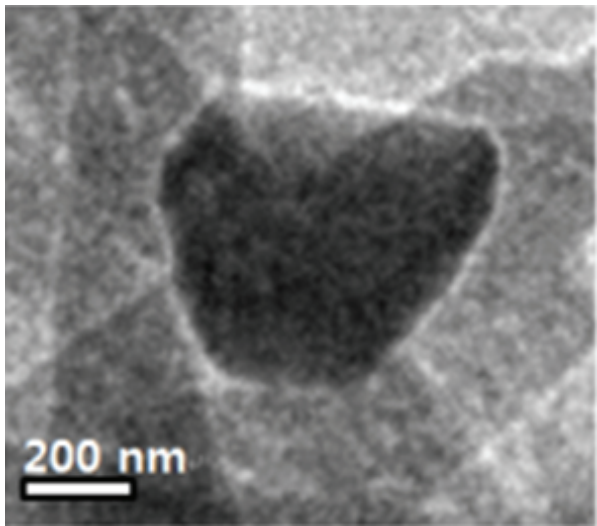

(c)

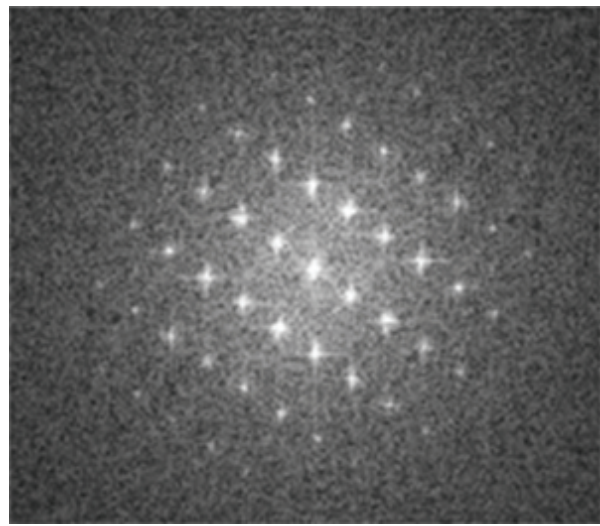

(e)

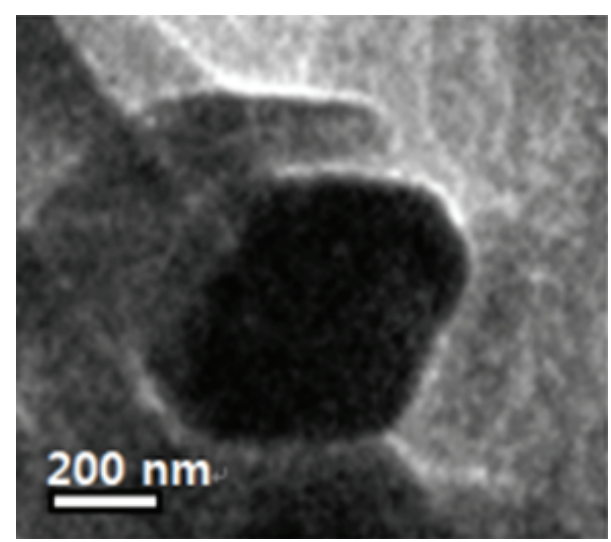

(b)

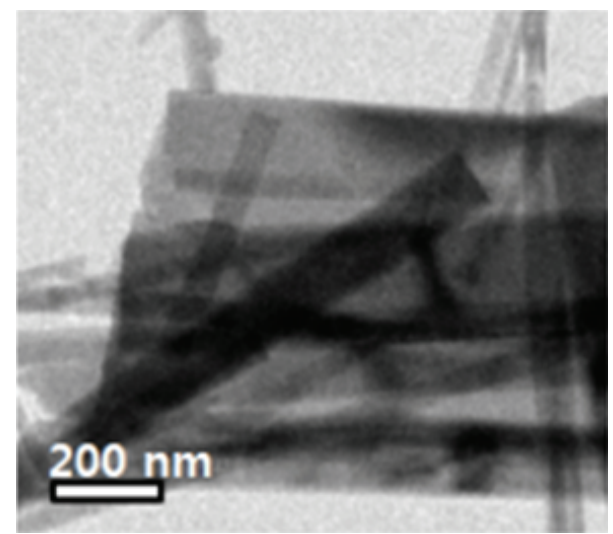

(d)

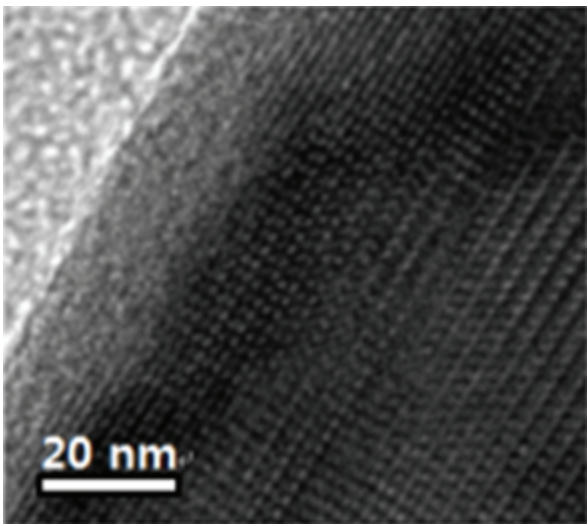

(f)

FIGURE 2: TEM images of polymer-assisted HA nanostructures with PAM concentrations of 2 and $4 \mathrm{~g} / \mathrm{L}$ (a, b) and hydrothermal reaction times of $6 \mathrm{hr}$ and (c, d) $12 \mathrm{hr}$. (e, f) FFT pattern and HRTEM image of (d).

nanoparticle synthesis in the presence of polymer was reported by Jeon et al. [30]. In the present study, we reported the PAM-assisted hydrothermal synthesis of hierarchically arranged flower-like HA nanostructures and proposed the formation mechanism. We also conducted in vitro cellular analysis to evaluate the use of these nanostructures as a possible material for biomedical applications.

\section{Experimental Details}

2.1. Materials and Methods. All chemicals were of analytical grade and were used without further purification. Calcium nitrate $\left(\mathrm{Ca}\left(\mathrm{NO}_{3}\right)_{2} \cdot 4 \mathrm{H}_{2} \mathrm{O}\right)$ and diammonium phosphate $\left(\mathrm{NH}_{4}\right)_{2} \cdot \mathrm{HPO}_{4}$ were used as calcium and phosphate sources. $\mathrm{Ca}\left(\mathrm{NO}_{3}\right)_{2} \cdot 4 \mathrm{H}_{2} \mathrm{O}$ and $\left(\mathrm{NH}_{4}\right)_{2} \mathrm{HPO}_{4}$ were separately dissolved 
in double distilled water. The $\mathrm{Ca}$ to $\mathrm{P}$ ratio was taken to be the stoichiometric ratio of HA (1.67). After stirring for $1 \mathrm{hr}$, different amounts $(2,3$, and $4 \mathrm{~g} / \mathrm{L}$ ) of polymer (polyacrylamide, PAM, Mw 10,000) were added to the calcium precursor solution. Next, $\left(\mathrm{NH}_{4}\right)_{2} \mathrm{HPO}_{4}$ solution was added to the $\mathrm{Ca}\left(\mathrm{NO}_{3}\right)_{2} \cdot 4 \mathrm{H}_{2} \mathrm{O} /$ polymer solution, after which the obtained suspension was transferred into a $50 \mathrm{~mL}$ Teflonlined stainless steel autoclave and heated at $180^{\circ} \mathrm{C}$ for 6 and $12 \mathrm{hrs}$. The suspension was then allowed to cool to room temperature, after which the obtained precipitate was washed several times with ethanol and distilled water. Finally, the powder was dried at $100^{\circ} \mathrm{C}$ before further characterization.

2.2. Characterization. All samples were analyzed in detail using different methods. Structural analysis was carried out using X-ray diffraction analysis (XRD, Rigaku, D/MAX $2500 \mathrm{H}$ ). Field emission scanning electron microscopy (FESEM, Helios 600) analysis was conducted to identify morphological variations due to different processing conditions. Further in-depth analysis was carried out by transmission electron microscopy (FE-TEM, Tecnai F30 S-Twin). Raman analysis was conducted using a laser Raman spectrometer (Renishaw inVia, Raman Microscope) at an output power of $10 \mathrm{~mW}$ of a $514 \mathrm{~nm} \mathrm{Ar}{ }^{+}$laser. Spectra were corrected using the LO-phonon mode of $\mathrm{Si}$ (100) substrates observed at $520.5 \mathrm{eV}$.

Human osteosarcoma cells (MG-63 cells) were cultured to determine the cell viability of polymer-assisted microstructures. Briefly, cells were cultured at $37^{\circ} \mathrm{C}$ in a humidified atmosphere of $5 \% \mathrm{CO}_{2}$ in air containing cell culture medium (DMEM media (phenol red free) Welgene), $10 \%$ fetal bovine serum (FBS, Welgene), $2 \mathrm{mM}$ L-glutamine, $1 \%$ penicillin, and streptomycin mixture (Antibiotic, Gibco). The cells were then seeded in 96-well microassay plates at a concentration of $1 \times 10^{4}$ cells/well and cultured for $24 \mathrm{~h}$. Sterilized HA nanoparticle samples were then added into the wells at a concentration of $100 \mu \mathrm{g} / \mathrm{mL}^{-1}$ and cocultured for 1 , 2, or 3 days. The cell proliferation or viability of cells was then determined using a CCK-8 kit (Dojindo, CK-04-13). Five samples were tested for each culture time period and the mean value was reported.

\section{Results and Discussion}

3.1. Surface Morphology Analysis. Figure 1 shows the surface morphology based on FESEM analysis of the polymerassisted HA microstructures. During short-term hydrothermal treatment $(6 \mathrm{hr})$ with a lower polymer concentration, a microstructure with a thickness of $250 \pm 30 \mathrm{~nm}$, and a length of more than a micrometer was generated. As the PAM concentration and reaction temperature increased, bunch-like structures were formed at the cost of a single nanostructure. In addition, the reaction time and the PAM concentration also influenced the thickness of the particle. By increasing these two parameters, the thickness was considerably reduced and a flower bunch-like structure was formed. The thickness of the plate-like structure decreased from $250 \mathrm{~nm}$ to $40 \mathrm{~nm}$ as the hydrothermal reaction time

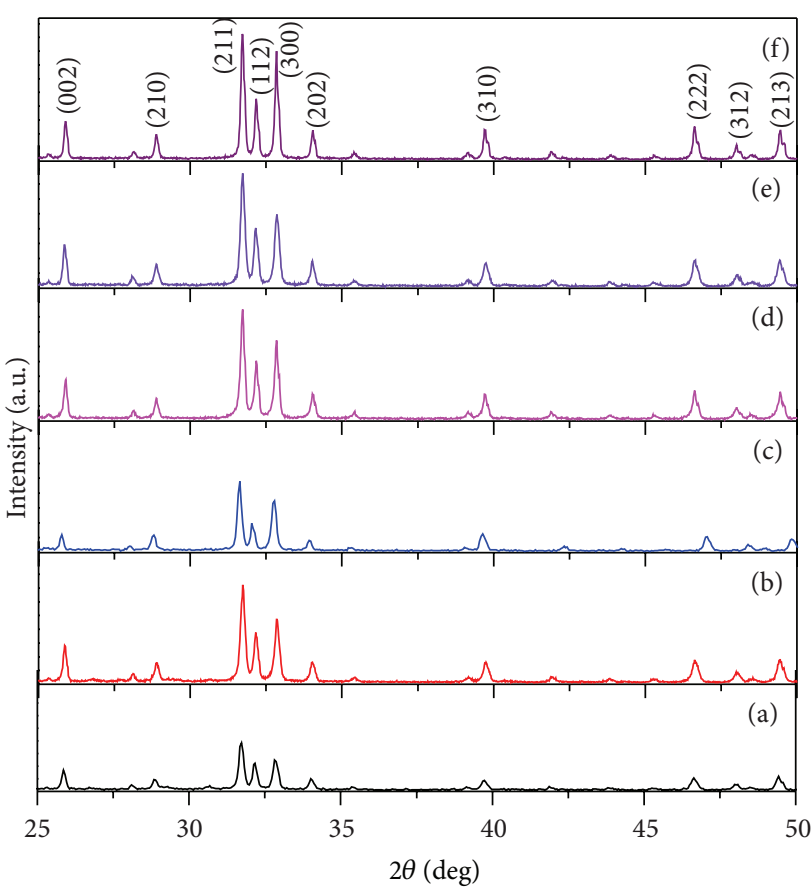

FIGURE 3: XRD pattern of polymer-assisted HA nanostructures with PAM concentrations of 2, 3, and $4 \mathrm{~g} / \mathrm{L}$ (a, c, and e) and hydrothermal reaction times of $6 \mathrm{hr}$ and $(\mathrm{b}, \mathrm{d}$, and $\mathrm{f}) 12 \mathrm{hr}$.

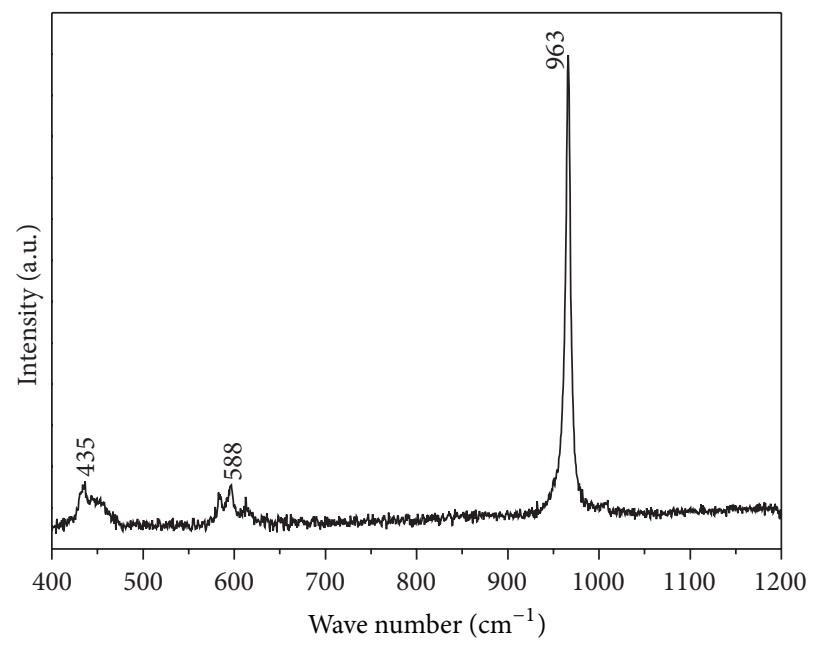

FIGURE 4: Raman spectrum of polymer-assisted HA nanostructures with PAM concentrations of $4 \mathrm{~g} / \mathrm{L}$ and hydrothermal reaction times of $12 \mathrm{hr}$.

and the polymer concentration increased. Further increases in polymer concentration ruined the plate-like structure.

Further insight into the nanostructure was obtained by the TEM analysis as shown in Figure 2. Individual nanosheets/plates were observed upon TEM analysis. The spots in the FFT pattern (Figure 2(e)) indicated that the nanostructure is highly crystalline in nature. Figure 2 confirms the decrease in the thickness of the sheet structure as observed upon SEM analysis. The TEM image confirmed the reduction in thickness with increased polymer concentration. 


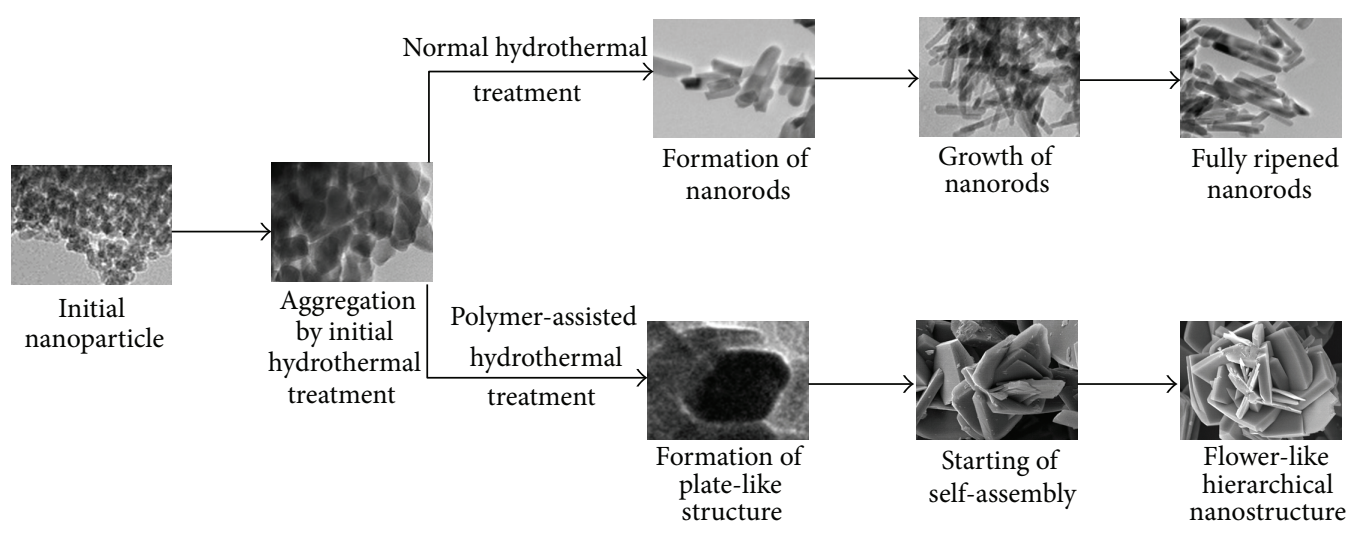

FIGURE 5: Schematic illustration of the formation mechanism of polymer-assisted HA nanostructures compared with pure HA nanorods.

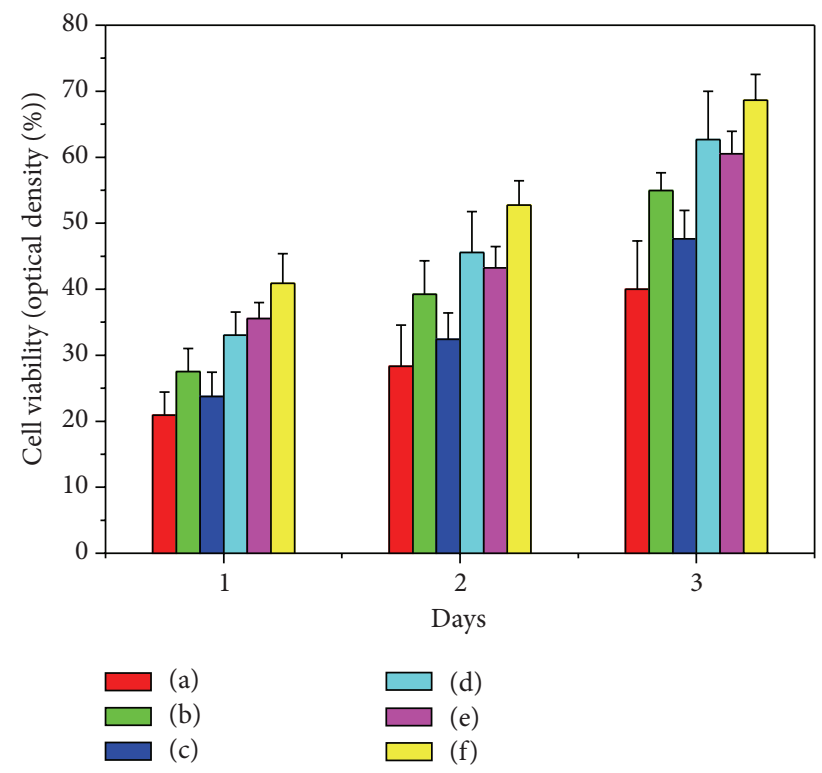

FIGURE 6: Cell viability on different days on polymer-assisted HA nanostructures with PAM concentration of 2,3 , and $4 \mathrm{~g} / \mathrm{L}$ and hydrothermal reaction times of $6 \mathrm{hr}(\mathrm{a}, \mathrm{c}$, and e) and $12 \mathrm{hr}(\mathrm{b}, \mathrm{d}$, and f).

Increased polymer concentration also induced formation of the floral structure, but it was not clearly observed upon TEM because it was ultrasonically agitated for TEM analysis.

3.2. Structural Analysis. Structural analysis of the polymerassisted HA nanoparticle was conducted using XRD. Figure 3 shows the XRD patterns of samples prepared under different conditions, which consisted of a well-crystalline phase with a hexagonal-structured HA (space group: P63/m (176)) [20]. No peaks corresponding to other secondary phases were observed in the samples. The reaction time in the hydrothermal method significantly influences the crystallinity of the material, thereby changing the intensity of the XRD peak. An initial reaction time of 6 hrs produced less peak intensity, while the intensity of the peak increased when the reaction time increased to $12 \mathrm{hrs}$.
The peaks present in the XRD patterns were readily indexed with the HA planes (002) at about $25.75^{\circ}$ and (211), (112), (300), and (202) in the range $31^{\circ}-35^{\circ}$, with the lattice parameters of $a=9.418 \AA$ and $c=6.884 \AA$ (JCPDS card no. 09-0432). Lattice parameters were calculated for all samples. Both 9.41-9.42 $\AA$ for the $a$-axis and 6.88-6.89 $\AA$ for the $c$-axis showed that there were no significant changes with polymerassisted hydrothermal treatment and that these values were very close to the reported value for bulk HA ( $a=9.418 \AA$ and $c=6.884 \AA$ ) [23]. The average crystallite sizes, $L$, of the samples were calculated in this study using the following Debye-Scherrer formula [32]:

$$
L=\frac{k \lambda}{\beta \cos \theta},
$$

where $k=0.94$ (shape factor), $\lambda$ is the wavelength of the radiation used (1.54056 $\AA$ ), $\beta$ is the full width at half maximum of the peak in radians, and $\theta$ is the Bragg angle. The calculations were carried out for the highly intense peaks in the XRD pattern (Figure 3). From the calculations, we observed that the crystallite size decreased from $22 \pm 5$ to $10 \pm 3 \mathrm{~nm}$ as the polymer concentration increased.

3.3. Raman Analysis. There was no significant change in the Raman peaks for the polymer-controlled synthesis of HA floral nanostructures. The peak at $963 \mathrm{~cm}^{-1}$ is characteristic of HA [23], which has a very strong $\mathrm{PO}_{4}$ group. Specifically, this peak reflects the symmetric stretching mode $\left(v_{1}\right)$ of the $\mathrm{PO}_{4}$ group ( $\mathrm{P}-\mathrm{O}$ bond). The degree of crystallinity of HA was identified using the position of this peak. When the peak was found at $963 \mathrm{~cm}^{-1}$, it was more ordered, highly crystalline noncarbonated apatite, while at $\sim 958 \mathrm{~cm}^{-1}$ it was polycrystalline apatite [23]. Hence, based on the data shown in Figure 4, the polymer-assisted HA produces the crystalline HA nanostructure well, confirming the XRD results. Along with this peak, additional weak peaks were found at $435 \mathrm{~cm}^{-1}$ (double degenerate bending mode $\left(v_{2}\right)$ of the $\mathrm{PO}_{4}$ group (O-P-O bond)) and 588 and $610 \mathrm{~cm}^{-1}$ (triply degenerate bending mode $\left(v_{4}\right)$ of the $\mathrm{PO}_{4}$ group (O-P-O bond)), which is also associated with the HA system [23]. Hence, the results of this study confirm that the addition of polymers 


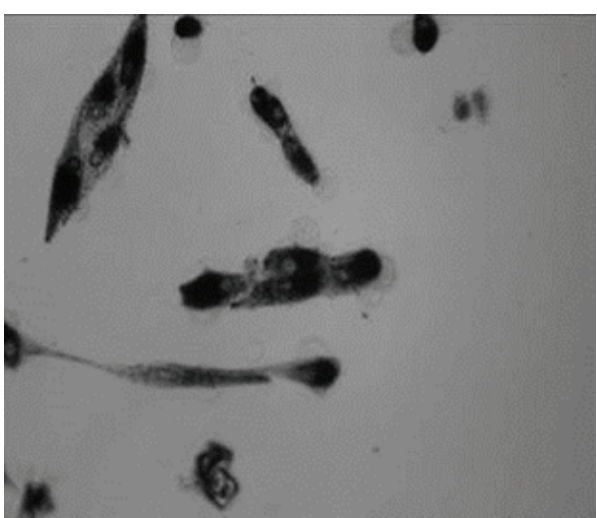

(a)

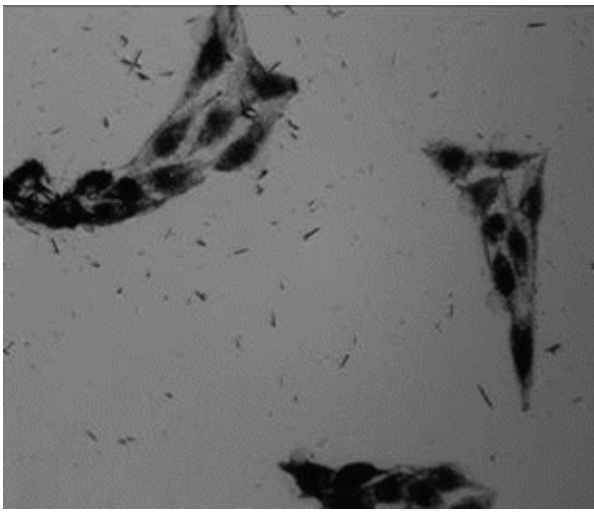

(c)

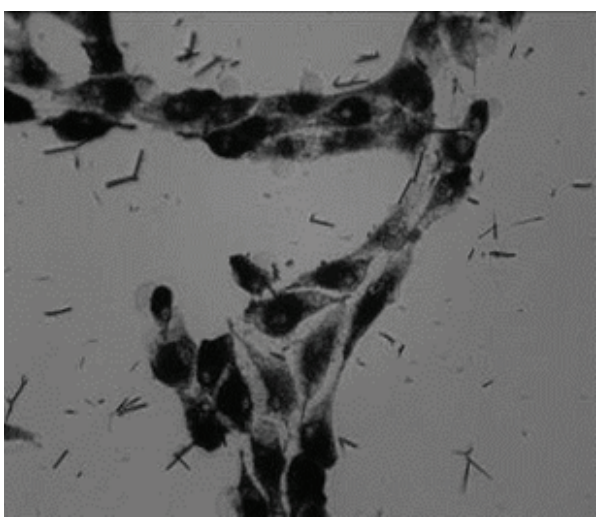

(e)

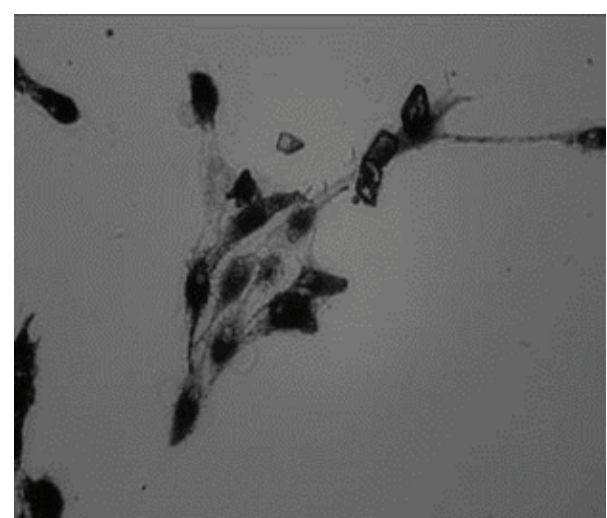

(b)

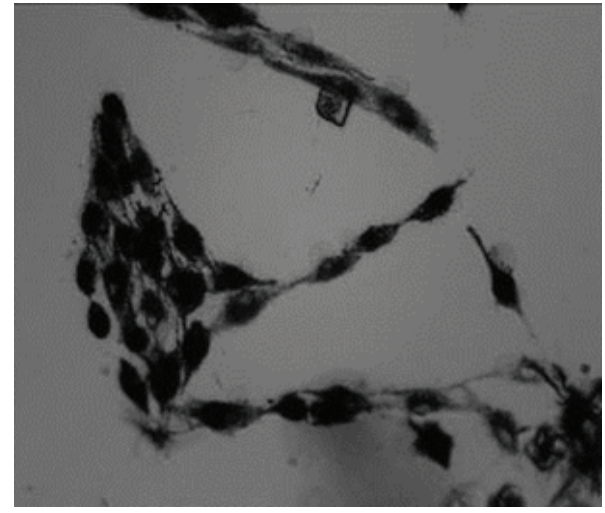

(d)

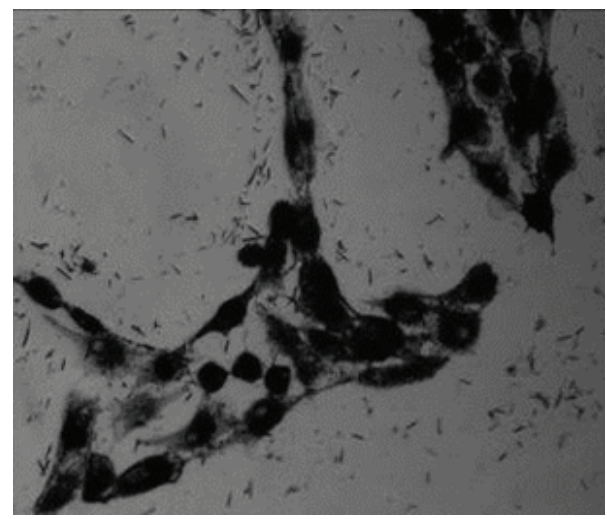

(f)

FIGURE 7: Optical images of cell spreading on polymer-assisted HA nanostructures with PAM concentrations of 2, 3, and $4 \mathrm{~g} / \mathrm{L}$ and hydrothermal reaction times of $6 \mathrm{hr}(\mathrm{a}, \mathrm{c}$, and e) and $12 \mathrm{hr}(\mathrm{b}, \mathrm{d}$, and $\mathrm{f})$.

in the preparation method does not affect the purity of the HA structure. Conversely, it provides better crystallinity and structural integrity.

3.4. Formation Mechanism. Based on the above experimental results, polymer-assisted self-assembly could be a formation mechanism for the nanostructured HA consisting of a nanosheet floral structure. In this mechanism, fine nanoparticles will be formed and grow as nanorods during initial nucleation in the hydrothermal treatment. The individual nanorods will then be aggregated into a sheet-like structure induced by the well-known Ostwald ripening mechanism [23], after which the nanosheets self-assemble into the hierarchically arranged flower-like nanostructure. Normally, HA will grow preferentially along the 001 direction or $c$-axis. It is likely that the use of PAM restricts growth along the 001 direction; therefore, we obtained the sheet structure. It has been reported that in PAM, the side chain contains a large number of amide ligands that are able to coordinate with inorganic ions (likely $\mathrm{Ca}^{2+}$ ) (the weakly exposed (001) face), leading to 
a lower surface energy and restriction of growth along the 001 direction [31]. For nanostructures, this polymer adsorption can only occur on one face; otherwise electroneutrality would be violated [31]. This may explain why we obtained the sheetlike structure instead of rod-like morphology. The schematic representation of the formation mechanism of floral-like HA was given in Figure 5 in comparison with the formation of nanorods to enable better understanding.

The degree of the assembly increased, whereas the thickness of the sheet decreased with increasing PAM concentration and reaction time. Finally, nanostructured HA with a flower-like morphology assembled from nanosheets was fabricated.

It is clear that the polymer plays an important role in the formation of these flower-like bunch nanostructures. It should be noted that the experiments that did not include PAM in the solution did not produce flower-like nanostructures, but elongated microparticles instead. When a smaller quantity of PAM ( $2 \mathrm{~g} / \mathrm{L})$ was added, compact HA plates with a thickness of $200 \mathrm{~nm}$ were obtained (Figure 1) upon initiation of the floral structure. As the PAM concentration increased, the thickness rapidly decreased. These results suggest that PAM molecules slow down the crystal growth along the 001 orientation; therefore, this method provided a simple approach to controlling the thickness of the HA plates. The polymer molecules were selectively adsorbed on the basal plane, after which crystal growth along the 001 direction was suppressed under these conditions, but the crystals were still able to grow sideways.

3.5. In Vitro Cellular Analysis. The cell proliferation of the MG-63 human osteosarcoma cell on polymer assisted HA nanocrystals as a function of days is shown in Figure 6. Cell viability varied with changes in the morphology of HA crystals. The cell proliferation rate revealed that there was inappreciable cytotoxicity on the prepared HA micro/nanoparticles on MG-63 cells. The cells were evenly proliferated around the flower-like structure. The particle size/thickness of the floral-like structure plays a role in cell attachment of the nanoparticle. At the same time, the crystallinity of the sample due to heat treatment by the hydrothermal route also played a crucial role in cell proliferation. Figure 7 shows the optical images of cell proliferation on the floral-shaped HA nanoparticles. Cell spreading was higher for highly crystalline and nanostructured samples. Further investigation and control of this specific nanostructure will lead to future drug loading and delivery applications. Since HA is highly biocompatible, it will be a promising material for drug delivery application, especially for orthopedic and dental applications.

\section{Conclusion}

We synthesized a polymer-assisted hydrothermal method for the preparation of hierarchical flower-like hydroxyapatite nanostructures. The hierarchical morphology of HA is dependent on the polymer concentration and hydrothermal treatment time. Initially, when there was a lower polymer concentration and short reaction time, a sheet-like structure with a thickness of more than $200 \mathrm{~nm}$ was generated and formation of a floral structure was initiated. The experimental results revealed that the hydroxyapatite flower-like structure possessed preferable biocompatible characteristics. The in vitro cell viability further revealed that the proliferation rate was higher for the hierarchically arranged HA nanostructure, confirming that size, uniformity, and crystallinity are important for tuning of the functional property. Thus, by controlling the preparation conditions and parameters, we can tune the functional property of the materials. Hence, the present HA nanostructure is a promising material for biomedical applications. Further, deciding parameters are under investigation, and possible use of this structure for drug loading and delivery is under consideration.

\section{Conflict of Interests}

The authors have no conflict of interests to declare.

\section{Acknowledgment}

This research was supported by Yeungnam University Research Grants in 2012.

\section{References}

[1] H. T. Ng, J. Li, M. K. Smith et al., "Growth of epitaxial nanowires at the junctions of nanowalls," Science, vol. 300, no. 5623, p. 1249, 2003.

[2] C. Burda, X. Chen, R. Narayanan, and M. A. El-Sayed, "Chemistry and properties of nanocrystals of different shapes," Chemical Reviews, vol. 105, no. 4, pp. 1025-1102, 2005.

[3] J. Yang, C. Li, X. Zhang et al., "Self-assembled 3D architectures of $\mathrm{LuBO}_{3}: \mathrm{Eu}^{3+}$ : phase-selective synthesis, growth mechanism, and tunable luminescent properties," Chemistry: A European Journal, vol. 14, no. 14, pp. 4336-4345, 2008.

[4] A. Chen, X. Peng, K. Koczkur, and B. Miller, "Super-hydrophobic tin oxide nanoflowers," Chemical Communications, vol. 10, no. 17, pp. 1964-1965, 2004.

[5] C. Zhang, Z. Cheng, P. Yang et al., "Architectures of strontium hydroxyapatite microspheres: solvothermal synthesis and luminescence properties," Langmuir, vol. 25, no. 23, pp. 13591-13598, 2009.

[6] L.-S. Zhong, J.-S. Hu, H.-P. Liang, A.-M. Cao, W.-G. Song, and L.-J. Wan, "Self-assembled 3D flowerlike iron oxide nanostructures and their application in water treatment," Advanced Materials, vol. 18, no. 18, pp. 2426-2431, 2006.

[7] J. Liu, Q. Wu, and Y. Ding, "Self-assembly and fluorescent modification of hydroxyapatite nanoribbon spherulites," European Journal of Inorganic Chemistry, no. 20, pp. 4145-4149, 2005.

[8] I.-S. Cho, D. W. Kim, S. Lee et al., "Synthesis of $\mathrm{Cu}_{2} \mathrm{PO}_{4} \mathrm{OH}$ hierarchical superstructures with photocatalytic activity in visible light," Advanced Functional Materials, vol. 18, no. 15, pp. 21542162,2008

[9] X. Duan, Y. Huang, Y. Cui, J. Wang, and C. M. Lieber, "Indium phosphide nanowires as building blocks for nanoscale electronic and optoelectronic devices," Nature, vol. 409, no. 6816, pp. 66-69, 2001. 
[10] Y. Cai, H. Pan, R. Xu, Q. Hu, N. Li, and R. Tang, "Ultrasonic controlled morphology transformation of hollow calcium phosphate nanospheres: a smart and biocompatible drug release system," Chemistry of Materials, vol. 19, no. 13, pp. 3081-3083, 2007.

[11] F. Favier, E. C. Walter, M. P. Zach, T. Benter, and R. M. Penner, "Hydrogen sensors and switches from electrodeposited palladium mesowire arrays," Science, vol. 293, no. 5538, pp. 22272231, 2001.

[12] S. Ghosh and O. Inganas, "Conducting polymer hydrogels as 3D electrodes: applications for supercapacitors," Advanced Materials, vol. 11, no. 14, pp. 1214-1218, 1999.

[13] D. R. Rolison and B. Dunn, "Electrically conductive oxide aerogels: new materials in electrochemistry," Journal of Materials Chemistry, vol. 11, no. 4, pp. 963-980, 2001.

[14] A. N. Shipway, E. Katz, and I. Willner, "Nanoparticle arrays on surfaces for electronic, optical, and sensor applications," ChemPhysChem, vol. 1, no. 1, pp. 18-52, 2000.

[15] T. Yonezawa, S. Onoue, and N. Kimizuka, "Self-organized superstructures of fluorocarbon-stabilized silver nanoparticles," Advanced Materialsno, vol. 13, no. 2, pp. 140-142, 2001.

[16] R. Maoz, E. Frydman, S. R. Cohen, and J. Sagiv, "Constructive nanolithography: site-defined silver self-assembly on nanoelectrochemically patterned monolayer templates," Advanced Materials, vol. 12, no. 6, pp. 424-429, 2000.

[17] J. Liu, K. Li, H. Wang, M. Zhu, H. Xu, and H. Yan, "Self-assembly of hydroxyapatite nanostructures by microwave irradiation," Nanotechnology, vol. 16, no. 1, pp. 82-87, 2005.

[18] L. C. Palmer, C. J. Newcomb, S. R. Kaltz, E. D. Spoerke, and S. I. Stupp, "Biomimetic systems for hydroxyapatite mineralization inspired by bone and enamel," Chemical Reviews, vol. 108, no. 11, pp. 4754-4783, 2008.

[19] F. Chen, Y.-J. Zhu, K.-W. Wang, and K.-L. Zhao, "Surfactant-free solvothermal synthesis of hydroxyapatite nanowire/nanotube ordered arrays with biomimetic structures," CrystEngComm, vol. 13, no. 6, pp. 1858-1863, 2011.

[20] A. J. Nathanael, D. Mangalaraj, P. Chi Chen, and N. Ponpandian, "Enhanced mechanical strength of hydroxyapatite nanorods reinforced with polyethylene," Journal of Nanoparticle Research, vol. 13, no. 5, pp. 1841-1853, 2011.

[21] S. V. Dorozhkin, "Calcium orthophosphates in nature, biology and medicine," Materials, vol. 2, no. 2, pp. 399-498, 2009.

[22] A. J. Nathanael, S. I. Hong, D. Mangalaraj, N. Ponpandian, and P. C. Chen, "Template free growth of novel hydroxyapatite nanorings: formation mechanism and their enhanced functional properties," Crystal Growth \& Design, vol. 12, no. 7, pp. 3565-3574, 2012.

[23] L. M. Rodríguez-Lorenzo and M. Vallet-Regí, "Controlled crystallization of calcium phosphate apatites," Chemistry of Materials, vol. 12, no. 8, pp. 2460-2465, 2000.

[24] X. Y. Zhao, Y. J. Zhu, F. Chen, B. Q. Lu, and J. Wu, "Nanosheetassembled hierarchical nanostructures of hydroxyapatite: surfactant-free microwave hydrothermal rapid synthesis, protein/DNA adsorption and $\mathrm{pH}$-controlled release," Crystal Engineering Communications, vol. 15, no. 1, pp. 206-212, 2013.

[25] Z. Li, Y. Xiong, and Y. Xie, "Selected-control synthesis of ZnO nanowires and nanorods via a PEG-assisted route," Inorganic Chemistry, vol. 42, no. 24, pp. 8105-8109, 2003.

[26] C. V. Krishnan, J. Chen, C. Burger, and B. Chu, "Polymerassisted growth of molybdenum oxide whiskers via a sonochemical process," Journal of Physical Chemistry B, vol. 110, no. 41, pp. 20182-20188, 2006.
[27] G. Xiong, X. Wang, L. Lu, X. Yang, and Y. Xu, "Preparation and characterization of $\mathrm{Al}_{2} \mathrm{O}_{3}-\mathrm{TiO}_{2}$ composite oxide nanocrystals," Journal of Solid State Chemistry, vol. 141, no. 1, pp. 70-77, 1998.

[28] Y.-H. Tseng, C.-S. Kuo, Y.-Y. Li, and C.-P. Huang, "Polymerassisted synthesis of hydroxyapatite nanoparticle," Materials Science and Engineering C, vol. 29, no. 3, pp. 819-822, 2009.

[29] J. Zhang, H. Liu, Z. Wang, N. Ming, Z. Li, and A. S. Biris, "Polyvinylpyrrolidone-directed crystallization of $\mathrm{ZnO}$ with tunable morphology and bandgap," Advanced Functional Materials, vol. 17, no. 18, pp. 3897-3905, 2007.

[30] S.-H. Jeon, P. Xu, B. Zhang et al., "Polymer-assisted preparation of metal nanoparticles with controlled size and morphology," Journal of Materials Chemistry, vol. 21, no. 8, pp. 2550-2554, 2011.

[31] Y. Peng, A.-W. Xu, B. Deng, M. Antonietti, and H. Cölfen, "Polymer-controlled crystallization of zinc oxide hexagonal nanorings and disks," Journal of Physical Chemistry B, vol. 110, no. 7, pp. 2988-2993, 2006.

[32] A. J. Nathanael, D. Mangalaraj, Y. Masuda, and N. Ponpandian, "Influence of fluorine substitution on the morphology and structure of hydroxyapatite nanocrystals prepared by hydrothermal method," Materials Chemistry and Physics, vol. 137, no. 3, pp. 967-976, 2013. 

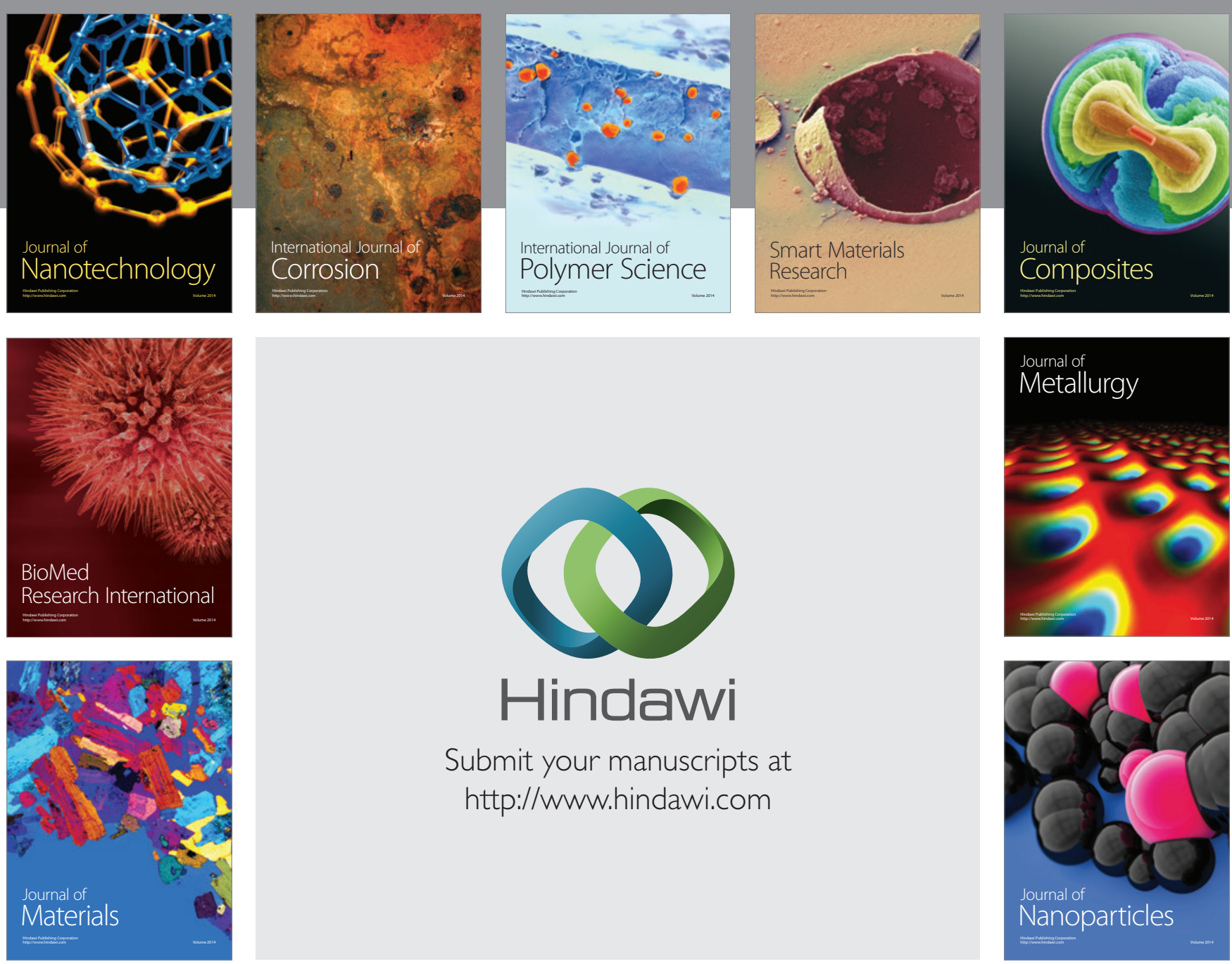

Submit your manuscripts at http://www.hindawi.com
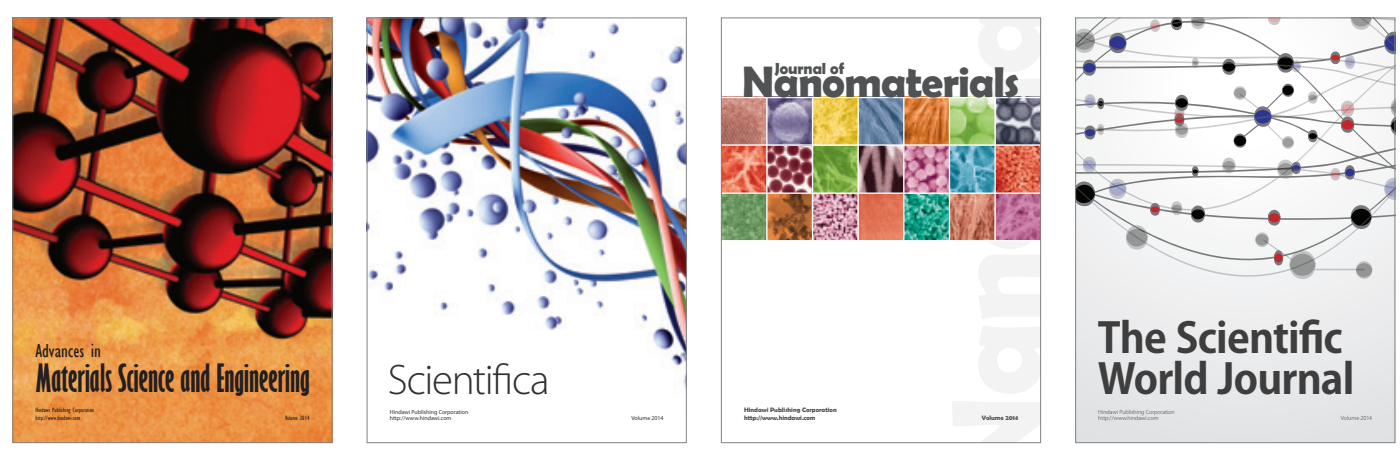

\section{The Scientific World Journal}
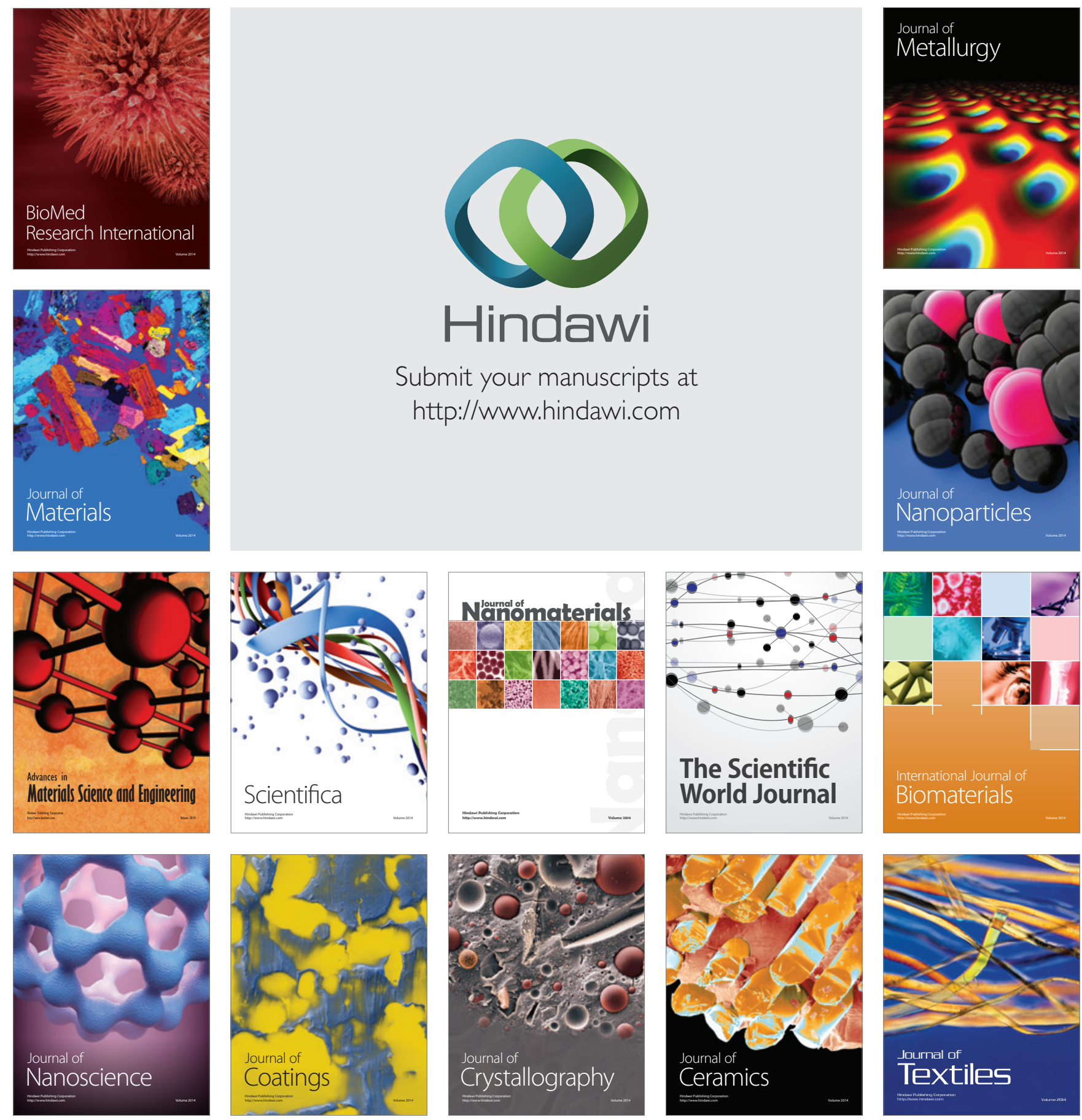